\title{
Biomechanical analysis of different implant-abutments interfaces in different bone types: An in silico analysis
}

\author{
Eduardo P. Pellizzer ${ }^{\mathrm{a}, *}$, Cleidiel A.A. Lemos ${ }^{\mathrm{a}}$, Daniel A.F. Almeida ${ }^{\mathrm{b}}$, Victor E. de Souza Batista ${ }^{\mathrm{a}, \mathrm{d}}$, \\ Joel F. Santiago Júnior ${ }^{c}$, Fellippo R. Verri ${ }^{\mathrm{a}}$
}

\author{
a Department of Dental Materials and Prosthodontics, Araçatuba Dental School, UNESP - Univ Estadual Paulista, Araçatuba, Sao Paulo, Brazil \\ ${ }^{\mathrm{b}}$ Department of Health Sciences, University of Sacred Heart - USC, Bauru, Sao Paulo, Brazil \\ ${ }^{\mathrm{c}}$ Department of Restorative Dentistry, Federal University of Alfenas, Alfenas, Minas Gerais, Brazil \\ d Department Prosthodontics, Presidente Prudente Dental School, University of Western São Paulo - UNOESTE, Presidente Prudente, Brazil
}

\section{A R T I C L E I N F O}

\section{Keywords:}

Implant-abutment interfaces

Diameter

Bone type

Finite element

\begin{abstract}
A B S T R A C T
The purpose of this study was to analyze the stress distribution of bone tissue around implants with different implant-abutment interfaces: platform switching (PSW); external hexagon (EH) and Morse taper (MT) with different diameters (regular: $\emptyset 4 \mathrm{~mm}$ and wide: $\varnothing 5 \mathrm{~mm}$ ), bone types (I-IV) and subjected to axial and oblique load conditions using three-dimensional finite element analysis (3D-FEA). Sixteen 3D models of various configurations were simulated using InVesalius, Rhinoceros 3D 4.0, and SolidWorks 2011 software, and processed using Femap 11.2 and NeiNastran 11.0 programs. Axial and oblique forces of $200 \mathrm{~N}$ and $100 \mathrm{~N}$, respectively, applied at the occlusal surface of prostheses. Maximum principal stress values were obtained from the periimplant cortical bone of each model. Statistical analyses were performed using ANOVA and Tukey's test for maximum principal stress values. Oblique loading showed higher tensile stress than axial loading $(P<0.001)$. Wide-diameter implants showed lower stress concentration rather than regular-diameter implants, regardless of both connection and bone type $(P<0.001)$. Under axial loading, wide-diameter EH implants with regular platforms showed more favorable stress distribution than PSW implants for axial loading $(P<0.001)$; however, under oblique loading, PSW implants exhibited lower stress concentrations $(P<0.001)$. Regular-diameter MT implants showed lower stress than EH implants $(P<0.001)$. Bone type IV showed higher stress in the cortical region than bone types I and II $(P<0.001)$, but no significant difference when compared with bone type III $(P>0.05)$. The conclusion drawn from this in silico is that MT implants should be considered for use in situations that preclude the placement of wide-diameter implants, particularly where bone types III and IV are concerned.
\end{abstract}

\section{Introduction}

Preserving the bone level around implants is considered an important challenge in implant dentistry [1]. Reports indicate that implant survival may be compromised by external factors - such as apical migration of peri-implant tissues and local bacterial colonization - that have been associated with an increased risk for bone resorption and subsequent rehabilitation failure [2].

In view of this, platform switching (PSW) concept has been considered as an alternative means of reducing marginal bone loss around the implants [3]. The PSW concept refers to selection of a reduced prosthetic platform in relation to implant diameter, thereby increasing the horizontal distance between the abutment-implant interface and bone tissue [4]. While some studies have attributed this influence due to the stress distribution in the long axis of the PSW implants [3], implant diameter is considered the more influential variable [5].

Bone tissue quality and quantity are also believed to directly influence stress distribution [6]. Some studies report low-density bone tissue to have limited stress tolerance and an increased risk for bone resorption [7]. Clinically, low-density bone is associated with reduced implant survival rates compared to those bone of normal-density [8]. With other biomechanical studies having found no correlation between bone density and stress distribution, however, consensus remains unresolved [3,9].

Morse taper (MT) implants incorporating PSW concept show better stress distribution than implants with external connections [1,3]. However, there is no consensus regarding whether regular-diameter MT implants are comparable to wide-diameter external hexagon (EH)

\footnotetext{
* Corresponding author at: Department of Dental Materials and Prosthodontics, Araçatuba Dental School, São Paulo State University (UNESP), 1193 Jose Bonifacio St, São Paulo, Brazil.

E-mail address: ed.pl@foa.unesp.br (E.P. Pellizzer).
} 
Table 1

Models description.

\begin{tabular}{|c|c|c|}
\hline Models & Bone type & Description \\
\hline M1 & I & $\mathrm{EH}-\emptyset 5 \times 10 \mathrm{~mm}$ with UCLA $4 \mathrm{~mm}$ (PSW) \\
\hline M2 & & $\mathrm{EH}-\varnothing 5 \times 10 \mathrm{~mm}$ with UCLA $5 \mathrm{~mm}$ \\
\hline M3 & & $\mathrm{EH}-\emptyset 4 \times 10 \mathrm{~mm}$ with UCLA $4 \mathrm{~mm}$ \\
\hline M4 & & MT $-\emptyset 4 \times 10 \mathrm{~mm}$ with Pilar Speed \\
\hline M5 & II & $\mathrm{EH}-\emptyset 5 \times 10 \mathrm{~mm}$ with UCLA $4 \mathrm{~mm}$ (PSW) \\
\hline M6 & & $\mathrm{EH}-\emptyset 5 \times 10 \mathrm{~mm}$ with UCLA $5 \mathrm{~mm}$ \\
\hline M7 & & $\mathrm{EH}-\varnothing 4 \times 10 \mathrm{~mm}$ with UCLA $4 \mathrm{~mm}$ \\
\hline M8 & & MT $-\emptyset 4 \times 10 \mathrm{~mm}$ with Pilar Speed \\
\hline M9 & III & $\mathrm{EH}-\varnothing 5 \times 10 \mathrm{~mm}$ with UCLA $4 \mathrm{~mm}$ (PSW) \\
\hline M10 & & $\mathrm{EH}-\varnothing 5 \times 10 \mathrm{~mm}$ with UCLA $5 \mathrm{~mm}$ \\
\hline M11 & & $\mathrm{EH}-\emptyset 4 \times 10 \mathrm{~mm}$ with UCLA $4 \mathrm{~mm}$ \\
\hline M12 & & MT $-\emptyset 4 \times 10 \mathrm{~mm}$ with Pilar Speed \\
\hline M13 & IV & $\mathrm{EH}-\varnothing 5 \times 10 \mathrm{~mm}$ with UCLA $4 \mathrm{~mm}$ (PSW) \\
\hline M14 & & $\mathrm{EH}-\emptyset 5 \times 10 \mathrm{~mm}$ with UCLA $5 \mathrm{~mm}$ \\
\hline M15 & & $\mathrm{EH}-\varnothing 4 \times 10 \mathrm{~mm}$ with UCLA $4 \mathrm{~mm}$ \\
\hline M16 & & MT $-\emptyset 4 \times 10 \mathrm{~mm}$ with Pilar Speed \\
\hline
\end{tabular}

implants in terms of stress distribution. Thus, the aim of this study was to evaluate the biomechanical behavior of different implant-abutment interfaces in relation to implant diameter (regular and wide) and bone tissue type (I-IV). The null hypotheses were as follows: (1) the implant diameter did not influence stress distribution in the cortical bone tissue, (2) the implant-abutment connection did not influence stress distribution in the cortical bone tissue, and (3) the quality of bone tissue did not influence stress concentration in the cortical bone tissue.

\section{Material and methods}

\subsection{In silico experimental design}

This research was designed to consider three variable factors: 1 ) diameter ( $\varnothing 4$ and $\varnothing 5 \mathrm{~mm}$ ); 2) implant-abutment interface (EH, MT, and PSW), and 3) bone tissue type (I-IV). Sixteen models were created to test these factors under axial and oblique loading (Table 1).

\subsection{Three-dimensional and finite-element analysis}

This methodology follows protocols from previous studies [1,3]. In silico three dimensional finite-element models were created to represent a mandibular bone section from the second molar region. Modeling was based on sagittal computerized tomography and accomplished using InVesalius software (CTI Renato Archer, Campinas, $\mathrm{SP}$, Brazil). Surface simplification was performed using Rhinoceros 4.0 software (NURBS Modeling for Windows, Seattle, WA, USA). Different bone tissues were simulated according to the Lekholm and Zarb classification for the bone tissue [10]: type I, consisting of cortical bone only; type II, consisting of a 2-mm cortical layer and trabecular bone of normal density; type III consisting of a 1-mm cortical layer and trabecular bone of normal density; and type IV, consisting of a 1-mm cortical layer and trabecular bone of low density.

Implant and abutment was obtained from a version of the original connection (Conexão Sistemas de Prótese Ltda, Aruja, SP, Brazil), and simplified using SolidWorks 2010 (SolidWorks Corp, Concord, MA, USA) and Rhinoceros 4.0 software. Each bone model was fitted with either an EH implant and UCLA abutment or MT implant with solid abutment. Implants were $10 \mathrm{~mm}$ in length and either $\emptyset 4.0$ or $\emptyset 5.0 \mathrm{~mm}$ in diameter (Fig. 1). The implant-supported crown was simulated with a screw-retained system for EH implant models, while MT models employed a cement-retained system with a cement layer thickness of 0.08$\mathrm{mm}$. Crowns were modeled on an artificial second molar tooth were simulated using a 3D scanner (MDX-20w, Roland DG, SP, Brazil) for digitalization (Odontofix Industria e Comercio de Material Odontologico Ltda., Ribeirao Preto, SP, Brazil). Feldspathic porcelain was used as the veneering material on external crown surfaces, and a nickel-chromium alloy was used of the framework.

After the modeling phase, all geometries were exported to finiteelement analysis software FEMAP 11.2 (Siemens PLM Software Inc., Santa Ana, CA, USA) for pre- and post-processing. FEMAP was used to create finite element models from meshes of tetrahedral parabolic solid elements. The mechanical properties of each simulated material were determined according to previously published studies (Table 2) $[11,12]$. All materials were considered isotropic, homogeneous, and linearly elastic.

The crown-abutment and abutment-implant interfaces were assumed to have symmetrical contacts, and all other contacts were also assumed to be symmetrically welded. Constraint conditions were fixed in all axes $(\mathrm{x}, \mathrm{y}$, and $\mathrm{z})$ at the anterior and posterior surfaces of each bone sections. All of the other model parts were unrestricted. A force of $200 \mathrm{~N}$ was distributed axially at four points on the internal slope of each cusps, and $100 \mathrm{~N}$ was distributed obliquely at two points on the internal slope of the lingual cusps (Fig. 1). Functional load was applied perpendicularly to the chewing surfaces of the cusps $[1,3]$.

After the pre-processing in FEMAP 11.2 software, the models were exported for mathematical calculation in the NeiNastran 11.0 software package (Noran Engineering, Westminster, CA, USA). With analytical problems solving complete, the models were then imported to FEMAP 11.2 for post-processing and visualization of stress maps. Maximum principal stress analysis was used to identify traction and compression stresses in peri-implant cortical bone due to the friable nature of the tissue. Measurement was in mega-Pascal (MPa) units, and tensile and compressive stresses were distinguishable by positive and negative values, respectively.

\subsection{Statistical analysis}

The highest 50 values for elements of maximum principal stress in peri-implant cortical bone [13] were compiled in Excel (Microsoft Office Excel, Redmond, WA, USA) and the spreadsheets exported to Sigma Plot 12.0 software package (Systat Software Inc., San Jose, CA, USA). Data were analyzed for normality (test Shapiro-Wilk test) and equal variance, before being subject to analysis of variance (ANOVA). Twoway ANOVA was conducted on diameter versus bone type, and abutment-implant interface versus bone type, under axial and oblique loading. Regions (mesial, buccal, lingual, and distal) and loading (axial and oblique) were analyzed using three-way ANOVA (connection, loading, and region). The Tukey post hoc test was used to identify differences between groups with significance set at $P<0.05$.

\section{Results}

\subsection{Diameter analysis}

Under axial loading, regular-diameter implants ( $\varnothing 4 \mathrm{~mm}$ ) showed higher compressive stress (mean: $1.324 \mathrm{MPa}$ ) than those wide-diameter (Ø $5 \mathrm{~mm}$ ) implants (mean: $0.636 \mathrm{MPa})(P<0.001)$. In bone type I, lower stress concentrations without significant influence of diameter $(P=0.553)$ were observed; however, in the other bone types the widediameter contributed to stress distribution more than the regular-diameter $(P<0.001)$ (Fig. 2). Under oblique loading, wide-diameter implants showed lower tensile and compressive stresses (mean: 3.078 $\mathrm{MPa}$ ) than the regular-diameter implants (mean: 9.773 MPa), regardless of both connection and bone type $(P<0.001)$ (Fig. 3).

\subsection{Implant-abutment interfaces analysis}

Maximum principal stress analysis revealed that regular-diameter MT implants show lower tensile stress than EH implants under both loadings $(P<0.001)$; Wide-diameter $\mathrm{EH}$ implants exhibited lower stress concentration than PSW implants under axial loading $(P<0.001)$ (Figs. 2 and 4). Under oblique loading, however, the PSW 

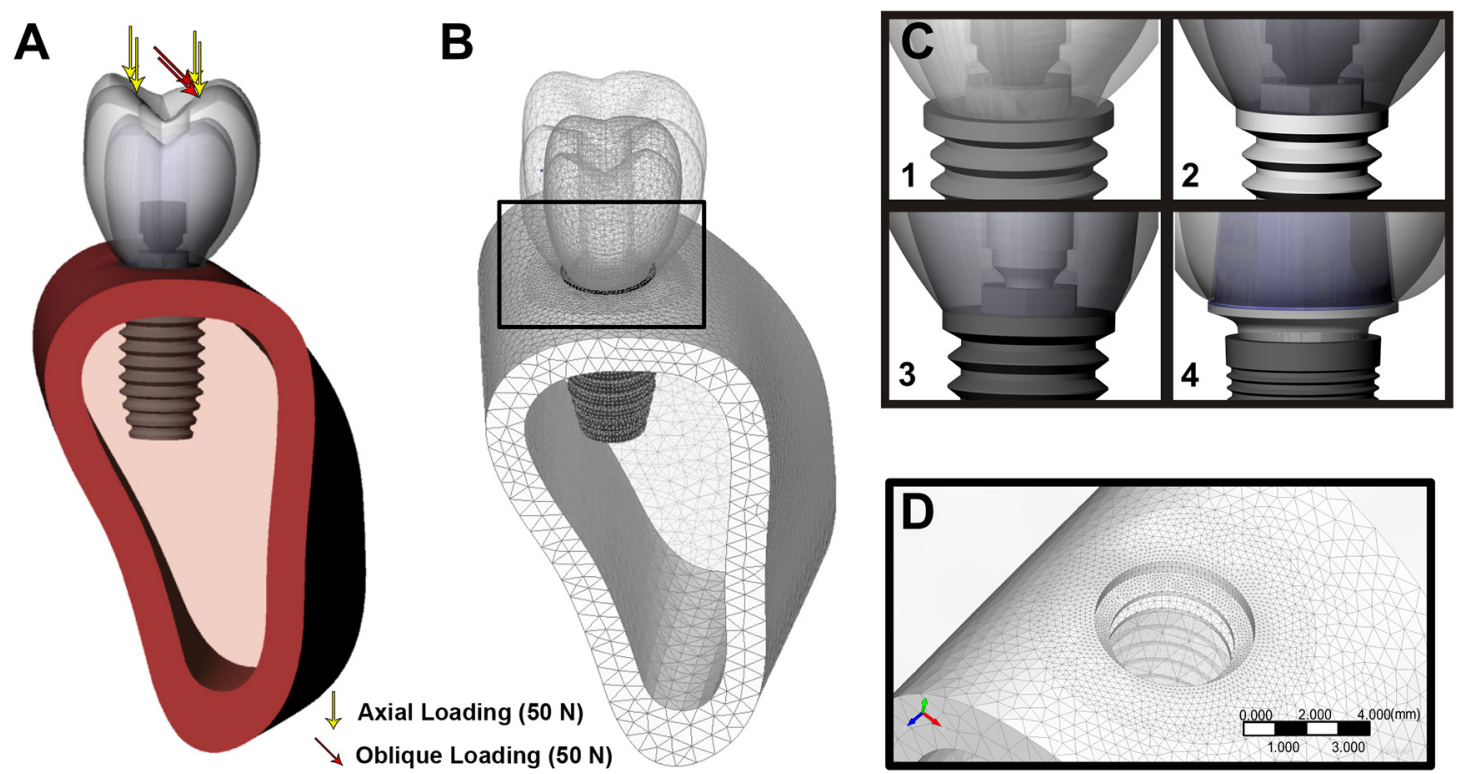

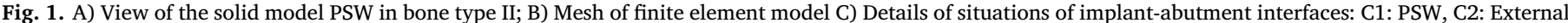
hexagon with regular diameter, C3: External hexagon with regular platform and C4: Morse taper with regular diameter. D) Detail of the analyzed area.

Table 2

Mechanical properties.

\begin{tabular}{llll}
\hline Materials & $\begin{array}{l}\text { Modulus of } \\
\text { elasticity (GPa) }\end{array}$ & $\begin{array}{l}\text { Poisson's ratio } \\
\text { (v) }\end{array}$ & References \\
\hline $\begin{array}{c}\text { Trabecular bone } \\
\text { (Bone type I, II } \\
\text { and III) }\end{array}$ & 1.37 & 0.3 & $\begin{array}{l}\text { Sevimay et al. } \\
{[11]}\end{array}$ \\
$\begin{array}{c}\text { Trabecular bone } \\
\text { (Bone type IV) }\end{array}$ & 1.10 & 0.3 & $\begin{array}{l}\text { Sevimay et al. } \\
{[11]}\end{array}$ \\
$\begin{array}{c}\text { Cortical bone } \\
\text { Titanium }\end{array}$ & 13.7 & 0.3 & $\begin{array}{l}\text { Sevimay et al. } \\
{[11]}\end{array}$ \\
Sevimay et al. \\
NiCr alloy & 110.0 & 0.35 & $\begin{array}{l}\text { Anusavice et al. } \\
{[12]}\end{array}$ \\
Feldspathic porcelain & 82.8 & 0.33 & $\begin{array}{l}\text { Sevimay et al. } \\
{[11]}\end{array}$ \\
\end{tabular}

implants demonstrated better stress distribution than other models, regardless of bone type $(P<0.001)$ (Figs. 3 and 4$)$.

\subsection{Bone type analysis}

Under axial loading, the bone type I showed lower stress compared to other bones types $(P<0.05)$ (Figs. 2 and 5). Bone type IV was found to be significantly different from bone types I and II $(P<0.001)$; however, no significant differences in terms of stress were observed between bone types III and IV $(P=0.329)$. Likewise, under oblique loading bone type IV proved significantly different from bone types I and II in terms of stress concentration $(P<0.001)$, yet no differences in stress were reported for bone types III and IV $(P=0.995)$, or for bone types I and II $(P=0.140)$ (Figs. 3 and 5$)$.

\subsection{Loading and region analysis}

Oblique loading showed higher tensile stress (6.576 MPa) in the cortical bone when compared with axial loading (0.943 MPa) $(P<0.001)$ (Figs. 2 and 3). Region analysis revealed higher tensile stress in the buccal region (5.269 MPa) than in the lingual (2.141 MPa), mesial $(3.714 \mathrm{MPa})$, or distal $(3.914 \mathrm{MPa})(P<0.001)$, whereas no significant differences between mesial and distal regions in terms of tensile stress $(P=0.338)$ were observed.

\section{Discussion}

The first hypothesis was rejected, since significant differences were observed in the stress distribution between wide-diameter and regulardiameter implants, regardless of load conditions. These results corroborate other biomechanical studies, which have reported more favorable stress distribution in cortical bone surrounding wide-diameter implants [5,14]. This may contribute clinically to a reduced rate of marginal bone loss around wide-diameter implants [15], and an indication for their use in low quality bone tissues such as that of the posterior maxillary region [15]. Even so, the risk of bone resorption and resultant tooth loss limits the placement of wide-diameter implants, especially in this region [16].

In this study, significant differences in stress distribution were observed between implant-abutment interfaces types, rejecting the second hypothesis. PSW implants showed favorable stress distribution when compared with regular-diameter implants; however, PSW implants showed similar stress distribution around the cortical bone tissue when compared with implants of the same diameter but with a regular platform. Thus, biomechanical effects can be attributed to the diameter and not the type of abutment-implant interface. These results are consistent with findings of other studies of PSW and EH interfaces, which have indicated that the biomechanical advantage to be related to the increased implant diameter, rather than centralization of stresses as an effect of reduced prosthetic platform [17]. Nevertheless, a recent systematic review reported that PSW implants have shown clinically lower marginal bone loss values when compared with implants with a regular platform [18]; this is probably related to biological rather than specific biomechanical factors.

Some studies have shown MT implants to be biomechanically and biologically superiority $[3,19]$, so, this study sought to determine whether regular-diameter MT implants and wide-diameter EH implants would present similar biomechanical behavior. Under axial loading, regular-diameter MT implants performed similarly to wide-diameter EH implants; however, under oblique loading conditions, wide-diameter EH implants showed better stress distribution than MT implants. Therefore, use of wide-diameter implants, independent of connection type, is recommended where it is possible to favors stress distribution and subsequent restorative treatment longevity. 


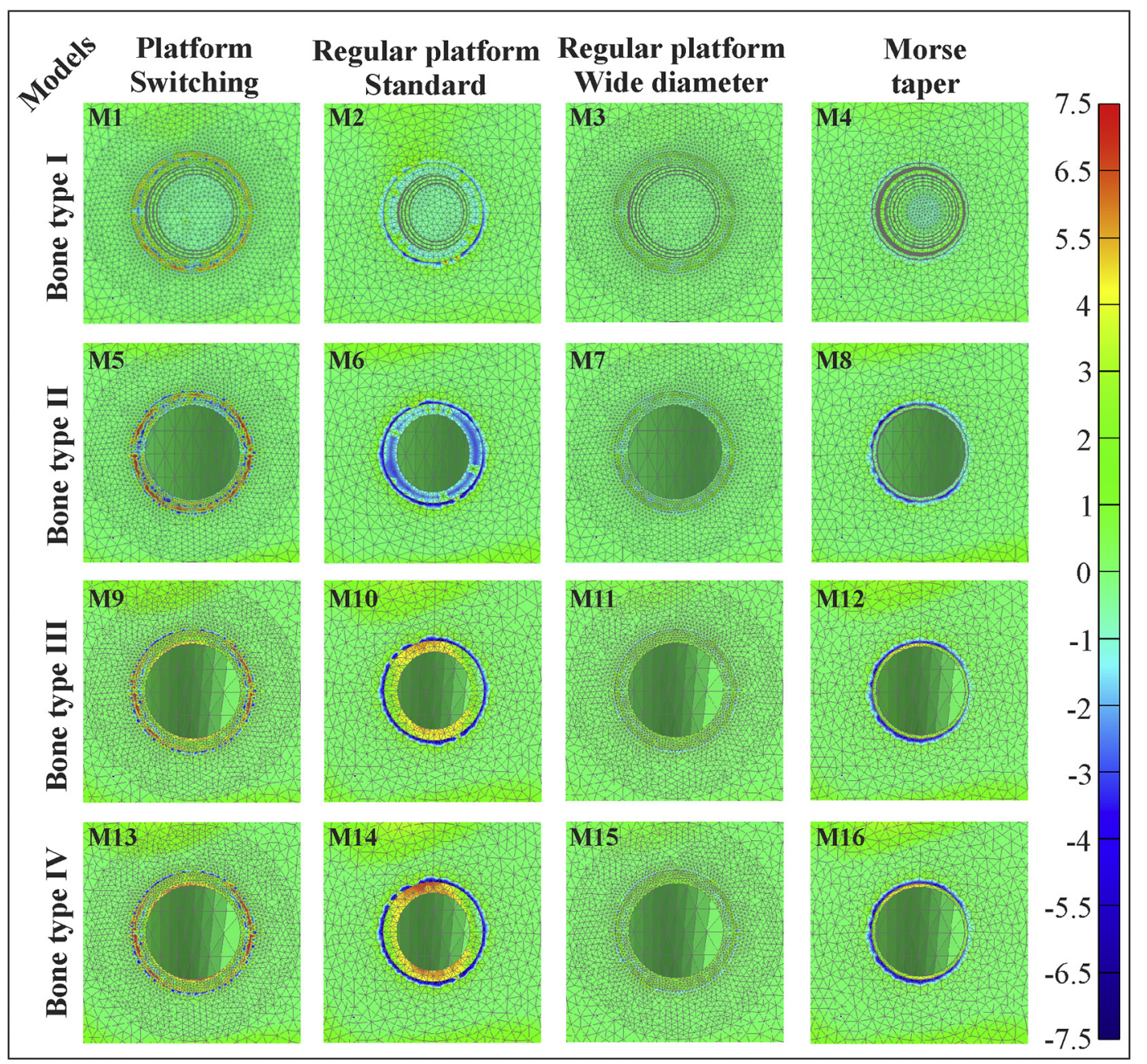

Fig. 2. Stress distribution in the cortical bone tissue by maximum principal stress (MPa) under axial loading.

Where circumstances preclude the placement of a wide-diameter implants, MT implants are recommended because they lead to lower stress in surrounding cortical bone tissue than do EH implants of the same diameter. This advantage relates to the location of the implantabutment interface. In, MT an internal connection centralizes stress within the long axis of the implant, thereby reducing the stress in the cortical area, whereas the EH implant connection is presented externally near cortical tissue, thereby contributing to increased stress and potential bone loss in the region [1,3]. These results may also could be related to the different prosthesis fixation methods used [20]. MT implants for rehabilitation of single-unit crown are recommended with cement-retained prosthesis [21], mainly with a solid abutment (onepiece) without screw fixation. These factors could contribute the favorable results for MT implants compared to $\mathrm{EH}$ implants from the same diameter.

Clinical evidence supports the findings of this biomechanical study, with lower rates of marginal bone loss surrounding MT than EH implants [22,23]. Moreover, the presence of a stable internal connection can reduce micromotion in the cortical bone region and provide a bacterial seal, leading to lower clinical values for marginal bone loss with MT implants [24].

The third hypothesis was rejected, since bone tissues types did demonstrate an influence on stress distribution. These results support a direct correlation between bone tissue density and stress concentration, especially under oblique loading [11]. Bone type IV, found in the posterior maxillary region, is lower in bone density than other bone types, and is associated with lower implant survival rates [8]. Cortical bone thickness is another factor that may influence stress responses in bone tissue [25]. According to Lekholm and Zarb [10], bone types III and IV showed relatively low cortical bone thickness $(1 \mathrm{~mm})$, which may contribute to higher stress in the region [3]. The above-mentioned findings were corroborated by the results of this study, which showed that despite the similarity of bone type III to types I and II in terms of density, it was between bone types III and IV that no significant differences were found, possibly due to a similar thickness of cortical bone $[3,11]$. Cortical bone thickness is also considered an important factor in rehabilitation planning. With an elasticity modulus approximately 10 times greater than that of trabecular bone tissue [11], cortical bone appears to protect this adjacent tissue, and consequently a loss or reduction of cortical bone is likely to compromise rehabilitation outcome [26].

Thus, reverse planning for implant placement should be accurate to avoid possible bone tissue overload and rehabilitation compromise. It is noteworthy that the conditions tested on cortical bone in this study did not exceed physiological limits for tensile and compressive stresses (72 to $76 \mathrm{MPa}$ and 140 to $170 \mathrm{MPa}$, respectively) [27]. Although the finiteelement method is considered a favorable tool for analysis of stress distribution, but it has certain limitations that may affect results. For example, materials properties of bone are assumed to be isotropic, homogeneous, and linear, unlike bone tissue in vivo, which exhibits anisotropic and non-homogeneous characteristics. Therefore, further randomized controlled trials should be conducted to gain a better understanding of the influence of these variables. 

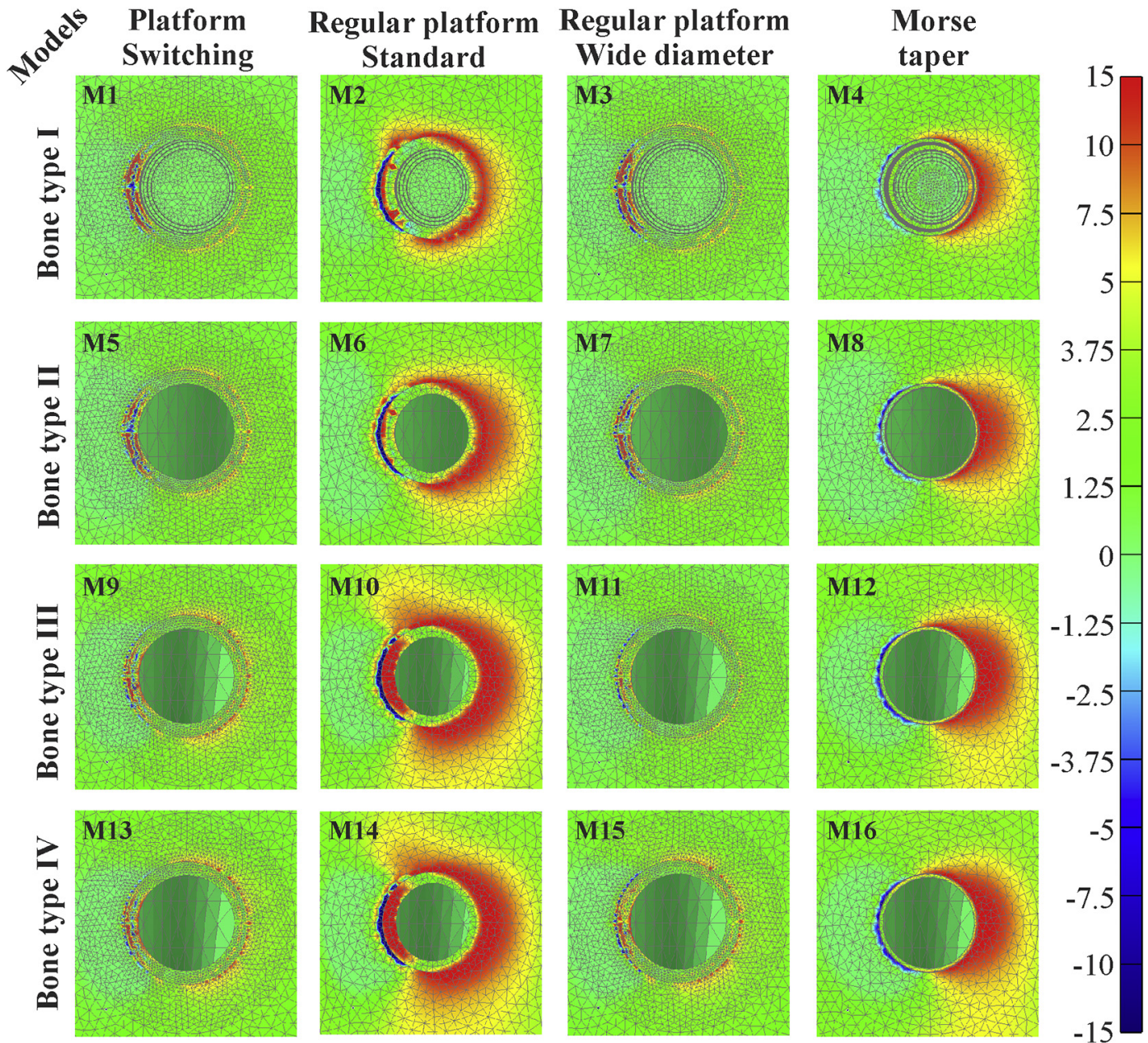

Fig. 3. Stress distribution in the cortical bone tissue by maximum principal stress (MPa) under oblique loading.

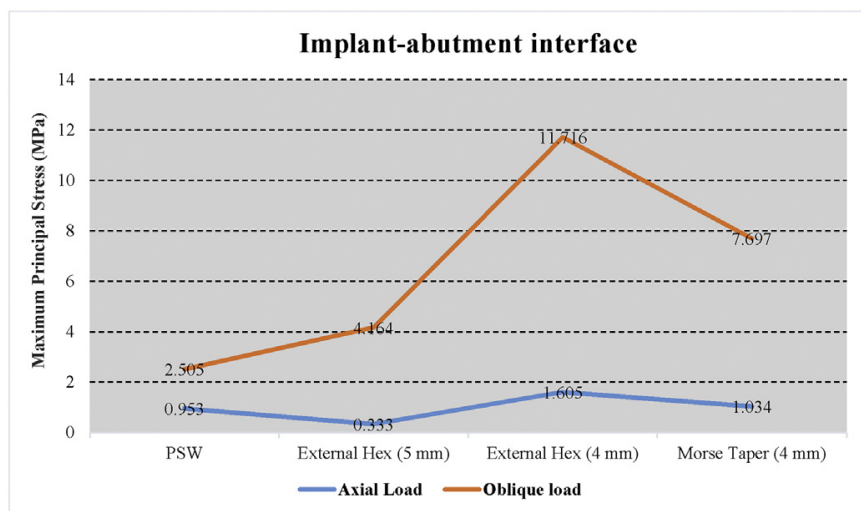

Fig. 4. Peak maximum of stress implant-abutment interfaces under axial and oblique loading.

\section{Conclusion}

Within the limitations of this in silico study, it can be concluded that wide-diameter implants show more favorable stress distribution than regular-diameter implants; MT implants show more favorable stress distribution than regular-diameter EH implants; and bone types III and IV show higher stress in the cortical region than bone types I and II. Thus, wide-diameter implants are recommended for first preference use, and where this is not possible, MT implants should be considered, particularly for bone types III and IV.

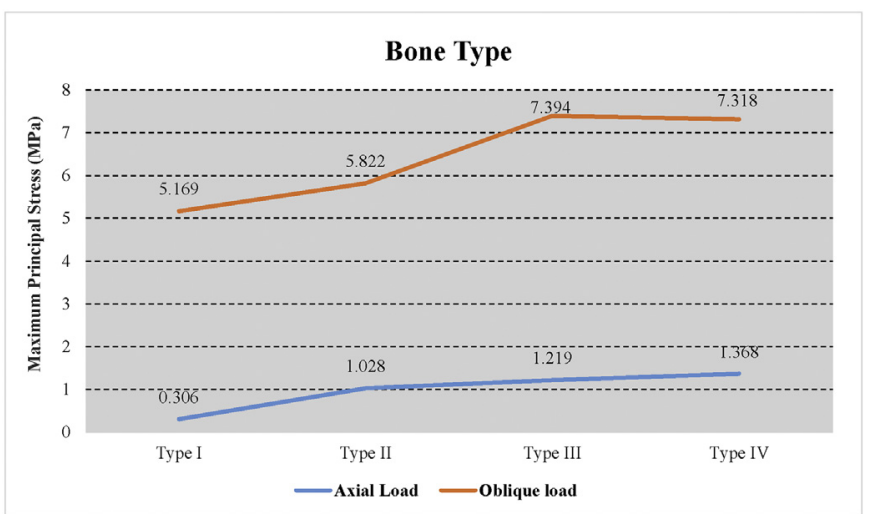

Fig. 5. Peak maximum of stress in the bone types under axial and oblique loading.

\section{Acknowledgements}

The authors thank Renato Archer Research Center for their supporting in the analysis and Conexão Sistemas de Prótese for their supporting in the design of implants and components. Study supported by Conselho Nacional de Desenvolvimento Científico e Tecnológico CNPq - \#grant: 303874/2010-4 and São Paulo State Foundation FAPESP: \# 09/16164-7. 


\section{References}

[1] D.A. de Faria Almeida, E.P. Pellizzer, F.R. Verri, J.F. Santiago Jr., P.S. de Carvalho, Influence of tapered and external hexagon connections on bone stresses around tilted dental implants: three-dimensional finite element method with statistical analysis, J. Periodontol. 85 (2014) 261-269.

[2] G. Charalampakis, I. Abrahamsson, O. Carcuac, G. Dahlen, T. Berglundh, Microbiota in experimental periodontitis and peri-implantitis in dogs, Clin. Oral Implants Res. 25 (2014) 1094-1098.

[3] J.F.J. Santiago, et al., Finite element analysis on influence of implant surface treatments, connection and bone types, Mater Sci Eng C Mater Biol Appl 63 (2016) 292-300.

[4] M.A. Atieh, H.M. Ibrahim, A.H. Atieh, Platform switching for marginal bone preservation around dental implants: a systematic review and meta-analysis, J. Periodontol. 81 (2010) 1350-1366.

[5] E.P. Pellizzer, et al., Stress analysis in platform-switching implants: a 3-dimensional finite element study, J. Oral Implantol. 38 (2012) 587-594.

[6] C.L. Lin, J.C. Wang, L.C. Ramp, P.R. Liu, Biomechanical response of implant systems placed in the maxillary posterior region under various conditions of angulation, bone density, and loading, Int. J. Oral Maxillofac. Implants 23 (2008) 57-64.

[7] S. Tada, R. Stegaroiu, E. Kitamura, O. Miyakawa, H. Kusakari, Influence of implant design and bone quality on stress/strain distribution in bone around implants: a 3dimensional finite element analysis, Int. J. Oral Maxillofac. Implants 18 (2003) 357-368.

[8] M.C. Goiato, D.M. dos Santos, J.F. Santiago Jr., A. Moreno, E.P. Pellizzer, Longevity of dental implants in type IV bone: a systematic review, Int. J. Oral Maxillofac. Surg. 43 (2014) 1108-1116.

[9] D. Cinar, P. Imirzalioglu, The effect of three different crown heights and two different bone types on implants placed in the posterior maxilla: three-dimensional finite element analysis, Int. J. Oral Maxillofac. Implants 31 (2016) e1-e10.

[10] U. Lekholm, G.A. Zarb, P.I. Branemark, G.A. Zarb, T. Albrektsson, Tissue-integrated prostheses, Tissue-Integrated Prostheses, Quintessence, Chicago, 1985.

[11] M. Sevimay, F. Turhan, M.A. Kilicarslan, G. Eskitascioglu, Three-dimensional finite element analysis of the effect of different bone quality on stress distribution in an implant-supported crown, J. Prosthet. Dent. 93 (2005) 227-234.

[12] K.J. Anusavice, B. Hojjatie, Stress distribution in metal-ceramic crowns with a facial porcelain margin, J. Dent. Res. 66 (1987) 1493-1498.

[13] L. Minatel, G.A.H. Kudo, D.A.F. Almeida, V.E. de Souza Batista, C.A.A. Lemos, J.F. Santiago Junior, E.P. Pellizzer, Effect of Different Types of Prosthetic Platforms on Stress-distribution Indental Implant-supported Prostheses, 71 (2017), pp. 35-42.

[14] G.A. de Paula, A.S. da Mota, A.N. Moreira, C.S. de Magahlães, T.P. Cornacchia, C.A. Cimini Jr, The effect of prosthesis length and implant diameter on the stress distribution in tooth-implant-supported prostheses: a finite element analysis, Int. J. Oral Maxillofac. Implants 27 (2012) e19-28.

[15] C. Ibanez, A. Catena, P. Galindo-Moreno, B. Noguerol, A. Magán-Fernández, F. Mesa, Relationship between long-term marginal bone loss and bone quality, implant width, and surface, Int. J. Oral Maxillofac. Implants 31 (2016) 398-405.

[16] C.A. Lemos, M.L. Ferro-Alves, R. Okamoto, M.R. Mendonca, E.P. Pellizzer, Short dental implants versus standard dental implants placed in the posterior jaws: a systematic review and meta-analysis, J. Dent. 47 (2016) 8-17.

[17] J.T. Hsu, L.J. Fuh, D.J. Lin, Y.W. Shen, H.L. Huang, Bone strain and interfacial sliding analyses of platform switching and implant diameter on an immediately loaded implant: experimental and three-dimensional finite element analyses, J. Periodontol. 80 (2009) 1125-1132.

[18] J.F.J. Santiago, F.R. Verri, E.P. Pellizzer, Platform-switching implants and bone preservation: a systematic review and meta-analysis, Int. J. Oral Maxillofac. Surg. 45 (2015) 332-345.

[19] C. Mangano, F. Iaculli, A. Piattelli, F. Mangano, Fixed restorations supported by Morse-taper connection implants: a retrospective clinical study with 10-20 years of follow-up, Clin. Oral Implants Res. 26 (2015) 1229-1236.

[20] C.A. Lemos, V.E. de Souza Batista, D.A.F. Almeida, J.F. Santiago Júnior, F.R. Verri, E.P. Pellizzer, Evaluation of cement-retained versus screw-retained implant-supported restorations for marginal bone loss: a systematic review and meta-analysis, J. Prosthet. Dent. 115 (2016) 419-427.

[21] C.A. Lemos, F.R. Verri, J.F. Santiago Júnior, D.A.F. Almeida, V.E.S. Batista, P.Y. Noritomi, E.P. Pellizzer, Retention system and splinting on Morse taper implants in the posterior maxilla by 3D finite element analysis, Braz. Dent. J. 29 (2018) 30-35.

[22] C.A.A. Lemos, F.R. Verri, E.A. Bonfante, J.F. Santiago Júnior, E.P. Pellizzer, Comparison of external and internal implant-abutment connections for implant supported prostheses. A systematic review and meta-analysis, J. Dent. 70 (2018) $14-22$.

[23] R.S. Pessoa, R.M. Sousa, L.M. Pereira, F.D. das Neves, F.J. Bezerra, R. Spin-Neto, et al., Bone remodeling around implants with external hexagon and Morse-taper connections: a randomized, controlled, split-mouth, clinical trial, Clin. Implant. Dent. Relat. Res. 19 (2017) 97-110.

[24] D. Tripodi, G. Vantaggiato, A. Scarano, V. Perrotti, A. Piattelli, G. Iezzi, S. D’Ercole, et al., An in vitro investigation concerning the bacterial leakage at implants with internal hexagon and Morse taper implant-abutment connections, Implant. Dent. 21 (2012) 335-339.

[25] N. Okumura, R. Stegaroiu, E. Kitamura, K. Kurokawa, S. Nomura, Influence of maxillary cortical bone thickness, implant design and implant diameter on stress around implants: a three-dimensional finite element analysis, J. Prosthodont. Res. 54 (2010) 133-142.

[26] X. Rodriguez-Ciurana, et al., Biomechanical repercussions of bone resorption related to biologic width: a finite element analysis of three implant-abutment configurations, Int. J. Periodontics Restor. Dent. 29 (2009) 479-487.

[27] G. Papavasiliou, P. Kamposiora, S.C. Bayne, D.A. Felton, Three-dimensional finite element analysis of stress-distribution around single tooth implants as a function of bony support, prosthesis type, and loading during function, J. Prosthet. Dent. 76 (1996) 633-640. 